\title{
New insights into the wasting mechanisms of chronic disease
}

\author{
Tommy Cederholm
}

\section{Abstract}

Catabolism in connection with disorders may be considered as an inevitable consequence of the disease or even as a physiological adaptation. Consequently, treatment focused against the emaciation in disease is often given low priority. However, the understanding of intrinsic mechanisms involved in the wasting of chronic disorders, its deleterious long-term effects and potential treatment possibilities has evolved largely in recent years, thus giving hope for the future development of complementary treatment modalities for diseases complicated by nutritional perturbations.

\section{Catabolism and disease}

The systemic neurohormonal response, i.e. catecholamine, cortisol and insulin, to isolated organ disease has been well characterized during the long course of exploration of the endocrine system. Such responses, although important, have not been able to explain fully why some diseases are associated with severe catabolism. An essential missing piece of the puzzle was disclosed in the mid-1980s when tumour necrosis factor- $\alpha(\mathrm{TNF}-\alpha) /$ cachectin was described as being responsible for the wasting during infectious disorders (1). The cytokine mediators of the inflammatory and immune systems have an array of functions all aiming at restoring homeostasis during illness. Some of these effects, such as anorexia, lipolysis and proteolysis, may, however, be deleterious to the individual patient in the long run. Gradually, a complex picture of interactions between organ failure, neurohormonal and immune/inflammatory activation and catabolic processes has emerged. The importance of these interactions for the wasting process was first established in cancer diseases, infections and trauma. Subsequently, it has appeared that such interactions also underlie emaciation in most chronic disorders, including chronic obstructive pulmonary disease (2) and chronic renal failure (3), and in the elderly with multiple chronic disorders (4).

In this issue of Scandinavian Journal of Nutrition, Dr Anker in his review describes the recent progress in understanding the mechanisms leading to cachexia during chronic heart failure, i.e. cardiac cachexia. Cardiac cachexia was described by Hippocrates: "the flesh is consumed and becomes water, ..., the shoulders, clavicles, chest, and thighs melt away". The prevalence of cardiac cachexia ranges between 5 and $25 \%$, depending on the kind of chronic heart failure populations studied (5). Previously the wasting mechanisms were only vaguely understood. Hypermetabolism, anorexia and hypoxia have been suggested (6). Bowel oedema was thought to impair nutrient absorption (7). These proposed mechanisms are probably still relevant for the development of cardiac cachexia. The recent studies of Dr Anker and others have firmly established the strong association between proinflammatory cytokine activity, e.g. TNF and interleukin-6 (IL-6), and cardiac cachexia, although the mechanisms triggering inflammation are still not understood, as depicted by Dr Anker.

\section{Therapeutic implications}

The new insights into the systemic character of many organ diseases open pathways for future treatment strategies, not only in chronic heart failure, but also in other organ disorders complicated by catabolism due to secondary systemic inflammation. Until today treatment of chronic heart failure has been directed towards the negative haemodynamic effects of the disorder. The recent introduction of the angiotensin-converting enzyme (ACE) inhibitors, e.g. captopril, represents a great achievement in heart failure treatment. The beneficial effects of ACE inhibitors have mainly been attributed to diminished cardiac workload by interference with the renin-angiotensin-aldosterone system. However, ACE inhibitors have subsequently been shown to possess anti-inflammatory properties (8) and it may be speculated that some of the beneficial effects of ACE inhibitors are conferred by such activities. For example, it was recently shown that reduced cardiac septum 
thickness after enalapril treatment in congestive heart failure patients was related to decreased inflammation (9). Anti-TNF treatment, as accomplished by TNF receptor blockade (etanercept) or antibody treatment against TNF (infliximab), has recently been shown to be effective in primary inflammatory disorders such as rheumatoid arthritis (10) and inflammatory bowel disease (11). However, such treatments have so far not been proven effective in cardiac congestion. A possible reason for the conflicting results may be that in, for example, chronic heart failure inflammation may be viewed as a two-edged adaptive response to the disease with both positive and negative influences on the disease progression. TNF blocking therapy may, under such conditions, abolish not only the negative effects of inflammation. Other cytokine modulating substances, e.g. megestrol acetate, thalidomide and pentoxifyllin, are being evaluated in various clinical conditions with wasting. Results are promising but still inconclusive $(12,13)$. The current challenge may be to determine the adequate level of inflammatory modification and to find the most appropriate patients to treat by anti-inflammatory means.

Research efforts such as those presented by Dr Anker and his colleagues will hopefully in the near future lead to pharmacological treatments that may complement and facilitate more conventional nutritional treatment in wasting disorders, thus contributing to the pursuit of sustaining malfunctioning catabolic patients to cope better with daily living.

\section{References}

1. Beutler B, Cerami A: Cachectin and tumor necrosis factor as two sides of the same coin. Nature 1986;320: 584-8.

2. Schols AM: Nutrition in chronic obstructive pulmonary disease. Curr Opin Pulm Med 2000;6:110-5.

3. Stenvinkel P, Heimburger O, Paultre F, Diczfalusy U, Wang T, Berglund L, Jogestrand T: Strong association between malnutrition, inflammation, and atherosclerosis in chronic renal failure. Kidney Int 1999;55:1899911.

4. Cederholm T, Jägrén C, Hellström K: Outcome of protein-energy malnutrition in elderly medical patients. Am J Med 1995;98:67-74.

5. Akner G, Cederholm T: Treatment of protein-energy malnutrition in chronic nonmalignant disorders. Am J Clin Nutr 2001;74:6-24.

6. Pittman JG, Cohen P: The pathogenesis of cardiac cachexia. N Engl J Med 1964;271:403-9.

7. Davidson JD, Goodman DS, Waldmann TA, Gordon RS. Protein-losing gastroenteropathy in congestive heart failure. Lancet 1961;i:899-903.

8. Peeters ACTM, Netea MG, Kullberg BJ, Thien T, van der Meer WM: The effect of renin-angiotensin system inhibitors on pro- and anti-inflammatory cytokine production. Immunology 1998;94:376-9.

9. Gullestad L, Aukhurst P, Ueland T, Espevik T, Yee G, Vagelos $\mathrm{R}$ et al: Effect of high-versus low-dose angiotensin converting enzyme inhibition on cytokine levels in chronic heart failure. Am Coll Cardiol 1999; 34:2061-7.

10. Maini RN, Feldmann M: Cytokine therapy in rheumatoid arthritis. Lancet 1996;348:824-5.

11. Blam ME, Stein RB, Lichtenstein GR: Integrating antitumor necrosis factor therapy in inflammatory bowel disease: current and future perspectives. Am J Gastroenterol 2001;9:1977-97.

12. Sliwa K, Skudicky D, Candy G, Wisenbaugh T, Sareli P: Randomised investigation of effects of pentoxifylline on left-ventricular performance in idiopathic dilated cardiomyopathy. Lancet 1998;351:1091-3.

13. Yeh SS, Wu SY, Lee TP, Olson JS, Stevens MR, Dixon $\mathrm{T}$ et al: Improvement in quality-of-life measures and stimulation of weight gain after treatment with megestrol acetate oral suspension in geriatric cachexia: results of a double blind, placebo-controlled study. J Am Geriatr Soc 2000;48:485-92.

Tommy Cederholm, MD, PhD

Department of Geriatric Medicine, Huddinge University Hospital, SE-I4I 86 Stockholm, Sweden.

E-mail: tommy.cederholm@ger.hs.sll.se 